\title{
Parkinson's disease and long-term exposure to outdoor air pollution: A matched case-control study in the Netherlands
}

\author{
Rosario Toro $^{\mathrm{a}, 1}$, George S. Downward ${ }^{\mathrm{b}, *, 1}$, Marianne van der Mark $^{\mathrm{b}}$, Maartje Brouwer ${ }^{\mathrm{b}}$, \\ Anke Huss $^{\mathrm{b}}$, Susan Peters ${ }^{\mathrm{b}, \mathrm{c}}$, Gerard Hoek ${ }^{\mathrm{b}}$, Peter Nijssen ${ }^{\mathrm{d}}$, Wim M. Mulleners ${ }^{\mathrm{e}}$, Antonetta Sas ${ }^{\mathrm{f}}$, \\ Teus van Laar', Hans Kromhout ${ }^{\mathrm{b}}$, Roel Vermeulen ${ }^{\mathrm{b}, \mathrm{h}}$ \\ ${ }^{a}$ Institute of Nutrition and Food Technology, University of Chile, Santiago, Chile \\ ${ }^{\mathrm{b}}$ Institute for Risk Assessment Sciences, Division of Environmental Epidemiology, Utrecht University, Utrecht, the Netherlands \\ ${ }^{\mathrm{c}}$ Department of Neurology, University Medical Centre Utrecht, Utrecht, the Netherlands \\ ${ }^{\mathrm{d}}$ Department of Neurology, Elisabeth-TweeSteden Hospital, Tilburg, the Netherlands \\ ${ }^{\mathrm{e}}$ Department of Neurology, Canisius-Wilhelmina Hospital, Nijmegen, the Netherlands \\ ${ }_{\mathrm{f}}^{\mathrm{f}}$ Department of Neurology, Vlietland Hospital, Schiedam, the Netherlands \\ ${ }^{\mathrm{g}}$ Department of Neurology, University Medical Centre Groningen, Groningen, the Netherlands \\ ${ }^{\mathrm{h}}$ Julius Center for Health Sciences and Primary Care, University Medical Center Utrecht, Utrecht, the Netherlands
}

\section{A R T I C L E I N F O}

Handling Editor: Zorana Jovanovic Andersen Keywords:

Air pollution

Parkinson's disease

Long-term exposure

Land-use regression

\begin{abstract}
A B S T R A C T
Background: There is some evidence to suggest an association between ambient air pollution and development of Parkinson's disease (PD). However, the small number of studies published to date has reported inconsistent findings.

Objectives: To assess the association between long-term exposure to ambient air pollution constituents and the development of PD.

Methods: Air pollution exposures (particulate matter with aerodynamic diameter $<10 \mu \mathrm{m}\left[\mathrm{PM}_{10}\right],<2.5 \mu \mathrm{m}$ $\left[\mathrm{PM}_{2.5}\right]$, between $2.5 \mu \mathrm{m}$ and $10 \mu \mathrm{m}\left[\mathrm{PM}_{\text {coarse }}\right]$, black carbon, and nitrogen oxides $\left[\mathrm{NO}_{2}\right.$ and $\left.\mathrm{NO}_{\mathrm{x}}\right]$ ) were predicted based on land-use regression models developed within the "European Study for Air Pollution Effects" (ESCAPE) study, for a Dutch PD case-control study. A total of 1290 subjects (436 cases and 854 controls). were included and 16 years of exposure were estimated (average participant starting age: 53). Exposures were categorized and conditional logistic regression models were applied to evaluate the association between ambient air pollution and PD.

Results: Overall, no significant, positive relationship between ambient air pollutants and PD was observed. The odds ratio (OR) for PD associated with an increase from the first quartile of $\mathrm{NO}_{2}\left(<22.8 \mu \mathrm{g} / \mathrm{m}^{3}\right)$ and the fourth $\left(>30.4 \mu \mathrm{g} / \mathrm{m}^{3}\right.$ ) was 0.87 (95\% CI: $\left.0.54,1.41\right)$. For $\mathrm{PM}_{2.5}$ where the contrast in exposure was more limited, the OR associated with an increase from the first quartile $\mathrm{PM}_{2.5}(<21.2 \mu \mathrm{g} / \mathrm{m} 3)$ to the fourth $(>22.3 \mu \mathrm{g} / \mathrm{m} 3)$ was 0.50 (95\% CI: $0.24,1.01)$. In a subset of the population with long-term residential stability $(n=632)$, an increased risk of PD was observed (e.g. OR for Q4 vs Q1 $\mathrm{NO}_{2}: 1.37,95 \% \mathrm{CI}: 0.71,2.67$ ).

Conclusions: We found no clear association between 16 years of residential exposure to ambient air pollution and the development of PD in The Netherlands.
\end{abstract}

\section{Background}

Parkinson's disease (PD) is one of the most common neurodegenerative diseases in the world, with a global prevalence of 6 million people in the year 2016 (Vos et al., 2017) and is estimated to affect over
9 million individuals by the year 2030 (Dorsey et al., 2007; Rossi et al., 2018). In addition to being a source of premature mortality, the progressive nature of PD means that it causes significant disability, ultimately being responsible for over 3 million lost disability-adjusted life years (DALYs) globally in 2016 (Hay et al., 2017).

${ }^{*}$ Corresponding author at: Institute for Risk Assessment Sciences (IRAS), Division of Environmental Epidemiology (EEPI), Utrecht University, Yalelaan 2, 3584 CM Utrecht, The Netherlands.

E-mail address: g.s.downward@uu.nl (G.S. Downward).

${ }^{1}$ Co-first author. 
The aetiology of PD is largely unknown, with a combination of different environmental and genetic factors being considered to be responsible (Kalia and Lang, 2015). Previous work has associated occupational exposure to pesticides as a risk factor for development of PD while cigarette smoking has been found to have a protective effect (van der Mark et al., 2012; van et al., 2014). Exposure to ambient air pollution has previously been suggested as a potential risk factor in the development of PD via mechanisms including inflammatory processes, oxidative stress, white matter abnormalities, and microglia activation (Block and Calderon-Garciduenas, 2009; Block et al., 2012).

Despite a potentially plausible biological basis for PD aetiology, the studies performed on exposure to ambient air pollution thus far have been inconsistent in their findings. Chen et al. reported an increased odds ratio (OR) for PD development in association with $\mathrm{PM}_{10}$ (OR comparing maximum exposure category $\left[>65 \mu \mathrm{g} / \mathrm{m}^{3}\right.$ ] to lowest [ $<54 \mu \mathrm{g} / \mathrm{m}^{3}$ ]: $1.35,95 \%$ CI: $\left.1.12,1.62\right)$ in a nested case-control study in Taiwan (Chen et al., 2017). A different Taiwanese study by Lee et al. also reported elevated ORs in association with exposure to traffic-derived $\mathrm{NO}_{\mathrm{x}}$ (OR per interquartile range [IQR] increase: 1.08, 95\% confidence interval [CI]: 1.04-1.12) in a large case-control study of Taiwanese men and women (Lee et al., 2016). Ritz et al. reported similar results with exposure to traffic-derived $\mathrm{NO}_{2}$ (OR per IQR increase: 1.09, 95\% CI: 1.03:1.16) in a Danish case-control study (Ritz et al., 2016). By contrast, Finkelstein et al. reported no association between traffic generated air pollution and PD, however a $10 \mathrm{ng} / \mathrm{m}^{3}$ increase in ambient manganese was associated with an OR of 1.03 (95\%CI: 1.00-1.07) (Finkelstein and Jerrett, 2007). Liu et.al reported no significant association between PM or $\mathrm{NO}_{2}$ exposures and PD risk in a nested casecontrol study in the USA (Liu et al., 2016). However, in subgroup analyses, they did report increased risks of PD among women who were exposed to high levels of $\mathrm{PM}_{10}$ (OR for highest quintile: 1.65, 95\% CI: $1.11,2.45)$ and non-smokers who were exposed to high levels of $\mathrm{PM}_{2.5}$ (OR: 1.29, 95\% CI: 1.01, 3.17). Prospective studies based in the USA by Palacios et al. reported no relationship between air pollution constituents and PD risk in their studies of 50,000 men and 115,000 women (Palacios et al., 2014; Palacios et al., 2017). Similar findings were reported by Cerza et al. who, in a cohort study of over a million people in Rome, reported no positive association between $\mathrm{PM}$ or $\mathrm{NO}_{2}$ and PD (Cerza et al., 2018).

Using a multi-centre PD case-control study, we aimed to investigate the relationship between long-term exposure to ambient air pollutants (particulate matter with aerodynamic diameter $<10 \mu \mathrm{m}$ $\left[\mathrm{PM}_{10}\right],<2.5 \mu \mathrm{m}\left[\mathrm{PM}_{2.5}\right]$, between $2.5 \mu \mathrm{m}$ and $10 \mu \mathrm{m}\left[\mathrm{PM}_{\text {coarse }}\right]$, black carbon, and nitrogen oxides $\left[\mathrm{NO}_{2}\right.$ and $\left.\mathrm{NO}_{\mathrm{x}}\right]$ ), and the development of PD.

\section{Methods}

\subsection{Study population}

The present study was an analysis of a multi-centre case control study on PD, designed to study the potential association between lifestyle, occupational and environmental risk factors, and PD, in The Netherlands. Details of the study and the subject selection are described elsewhere (van et al., 2014). In brief, PD cases and their matched controls were identified and recruited from five hospitals located in four cities (Groningen, Rotterdam, Nijmegen, and Tilburg) in The Netherlands between April 2010 and June 2012 (Fig. S1). Within each hospital, a neurologist reviewed the medical records of patients with a diagnosis of PD. Individuals were eligible as cases if they were initially diagnosed between January 2006 to December 2011 and were still alive at time of recruitment $(n=1001)$. Each enrolled case was paired with two controls, who visited the same hospital within the same time-frame as cases ( \pm 3 years). Controls were matched by hospital, visiting date, gender, and age. Controls were patients diagnosed with non-neurodegenerative and peripheral neurological diseases (i.e. median nerve neuropathy, ulnar nerve neuropathy, thoracic and lumbar disc disease and sciatica), which were assumed to not share the same pathological mechanisms as PD. Cases and controls resided in the same region as the hospital they visited. The participation rate among cases and controls was $45 \%$ and $35 \%$, respectively. If all controls assigned to a case declined to participate or did not respond, the two next best-matched potential controls were invited. Therefore it was possible that one control served as a control for multiple cases, which occurred 83 times in the current study. Initially, 448 cases were enrolled, however, for four of them, no suitable controls were found and were consequently excluded, resulting in 444 cases and 876 controls.

The medical ethics committee of St. Elisabeth Hospital Tilburg provided ethical approval for the study. All participants gave written informed consent for inclusion in the study.

\subsection{Data collection}

Cases and controls were interviewed via telephone by trained interviewers between April 2010 and June 2012. Information on demographics, medical history, lifestyle factors, diet, occupational pesticide use, occupation, and a detailed residential history of the participants was collected. The residential history listed all addresses the participant lived at for at least one year, and the first and last year the participant inhabited each address. The addresses were subsequently geocoded to assess residency-based environmental exposures (Brouwer et al., 2017).

\subsection{Exposure assessment}

Exposure to air pollutants at the residential address(es) of study participants were predicted using Land Use Regression (LUR) models developed within the ESCAPE project (Beelen et al., 2013; Eeftens et al., 2012). In brief, concentrations of $\mathrm{NO}_{2}, \mathrm{NO}_{\mathrm{x}}, \mathrm{PM}_{2.5}, \mathrm{PM}_{10}, \mathrm{PM}_{\text {coarse }}$, and $\mathrm{PM}_{2.5}$ absorbance were measured at multiple sites (40 sites for particulate matter and 80 sites for $\mathrm{NO}_{2}$ and $\mathrm{NO}_{\mathrm{x}}$ ) within The Netherlands. Measurements were conducted in 2009 across three 14-day periods, spread over the seasons to derive their annual average. Subsequently, LUR models were developed by including geographic variables such as traffic intensity, land use and population density in order to explain the spatial variability of the pollutants' concentrations. The final models for each of the pollutants included three to seven predictor variables and explained $86 \%\left(\mathrm{NO}_{2}\right), 87 \%\left(\mathrm{NO}_{\mathrm{x}}\right), 92 \%\left(\mathrm{PM}_{2.5}\right.$ absorbance), $51 \%$ $\left(\mathrm{PM}_{\text {coarse }}\right), 67 \%\left(\mathrm{PM}_{2.5}\right)$ and $68 \%\left(\mathrm{PM}_{10}\right)$ of concentration variability.

Using the geocoded residential history of study participants, the LUR models were used to estimate the annual ambient air pollution at each participant's addresses. For participants who lived at different addresses at the same year, concentrations were averaged to give the concentration for that year. The modelled concentrations obtained from 2009 were assumed constant for the years 2010 through 2011 while the concentrations from 1992 to 2008 were back extrapolated using data from routine background monitoring network sites in The Netherlands. Back extrapolation was performed using the absolute and relative differences in measurements between the back extrapolated years (1992 to 2008) and 2009 (Beelen et al., 2014). We did not back extrapolate further than 1992 because there was no routine monitoring data available for all pollutants before 1992 .

The annual air pollutant concentrations for each participant from 1992 to the year before case diagnosis (cases) or the index year of the matched case diagnosis (controls) were averaged to provide a mean ambient concentration for each participant.

\subsection{Statistical analysis}

Subjects for whom $>50 \%$ of the addresses between 1992 until the year before onset/index year were missing, were excluded ( 6 cases, 6 controls). If the subject excluded was a case, its matched controls were also excluded. If the subject excluded was a control, however, it was 
excluded with its case only if this was the only control available. This resulted in a total of 7 cases and 18 controls being excluded. Additionally, one case had missing data for one of the covariates and was removed with its matched controls.

Average annual air pollution exposure was divided in quartiles based on the exposure distribution among the controls. We used conditional logistic regression models to calculate the odds ratio (OR) and 95\% confidence intervals (CI) to determine the association between average residential exposure to air pollutants and PD. Additionally, $p$ values for linear trend were calculated using the category value () of each quartile as a continuous variable. We specified two levels of adjustments for confounding covariates in our models. Model 1 was adjusted for educational level, smoking status and family history of PD. In model 2, we additionally adjusted for area social economic status (SES, percentage high income at the neighbourhood level of residency). Subjects with complete information on variables for models 1 and 2 were included in the analysis (436 cases and 854 controls).

Several sensitivity analyses were performed. First, we assessed the possible linear association between residential air pollution and PD by using the exposure as a continuous variable. Second, as pesticide exposure has previously been found to be relevant to PD risk, we evaluated the impact of residential exposure to specific pesticides - selected on the basis of prior relevance to PD risk (Benomyl, Lindane, Paraquat, and Maneb) - used on commercial crops within $100 \mathrm{~m}$ of a participant's residence on any relationship between air pollution and PD risk (Brouwer et al., 2017). Third, we explored the possible selection bias among the controls and their diseases by excluding each control disease one at a time. Fourth, assuming that residential mobility could result in exposure misclassification, we restricted the analyses to participants who did not move for either 14 years before or after 1992, separately. This time period was selected so as to maximize available sample size while still representing long term (i.e. $>10$ years) residential stability. Fifth, we assessed possible effect modification of smoking status and sex via stratified analysis. Last, we studied the heterogeneity in stratified analysis by hospital to determine whether results were influenced unduly by a specific hospital in the study (Higgins and Thompson, 2002). In these sensitivity analyses, to include the largest possible number of cases and controls when excluding diseases, restricting analyses and stratifying by covariates, matching was discarded and we used unconditional logistic regression (matching variables were used as additional adjustment variables).

All statistical analyses were performed using SAS version 9.4 with $p$ values $<0.05$ being used to indicate statistical significance.

\section{Results}

In total, 436 patients with PD and 854 matched controls were included for analysis. Demographic characteristics are presented in Table 1. As has been previously described (Kalia and Lang, 2015), a higher prevalence of PD was seen among men versus women $(63.1 \%$ vs $36.9 \%$ ). The median age of PD diagnosis was approximately 69 years old. Cases had a higher level of education than controls $(72.5 \%$ had high level of education compared to $65.2 \%$ in controls, $p<0.05$ ) and were more often never-smokers ( $46.6 \%$ vs $28.1 \%$, p < 0.05 ). A family history of PD was also higher in cases than controls $(14.0 \%$ vs $6.7 \%$, $\mathrm{p}<0.05$ ).

On average, approximately 16 years of air pollution exposure (prior to diagnosis) was estimated per person. The mean annual concentration for each pollutant is presented in Table 2, stratified by disease status. Mean concentrations of $\mathrm{NO}_{2}, \mathrm{NO}_{\mathrm{x}}, \mathrm{PM}_{2.5}, \mathrm{PM}_{10}, \mathrm{PM}_{\text {coarse }}$ and $\mathrm{PM}_{2.5}$ absorbance did not differ significantly between cases and controls. Contrast in exposure was lower for $\mathrm{PM}_{2.5}$ and $\mathrm{PM}_{10}$ compared to $\mathrm{NO}_{2}$ and $\mathrm{NO}_{\mathrm{x}}$. Correlations between pollutants were moderate to high $(0.49$ to 0.87 ). The highest correlation observed was between $\mathrm{NO}_{2}$ and $\mathrm{PM}_{2.5}$ absorbance (0.87 - Table S1).

The ORs of nearly all air pollutants were decreased among the
Table 1

Demographic characteristics of the study population.

\begin{tabular}{|c|c|c|c|}
\hline \multirow[t]{2}{*}{ Characteristics } & \multirow{2}{*}{$\frac{\text { PD patients }}{(n=436)}$} & \multirow{2}{*}{$\begin{array}{l}\text { Controls } \\
(n=854)\end{array}$} & \multirow[t]{2}{*}{$P$ value } \\
\hline & & & \\
\hline Male, n (\%) & $275(63.1)$ & $540(63.2)$ & 0.95 \\
\hline Age, y, median (IQR) ${ }^{\mathrm{a}}$ & $\begin{array}{l}68.8 \\
(62.5-74.0)\end{array}$ & $\begin{array}{l}69.2 \\
(62.9-74.4)\end{array}$ & 0.48 \\
\hline Education, n (\%) & & & 0.02 \\
\hline Elementary school & $120(27.5)$ & $297(34.8)$ & \\
\hline Middle school/high school & $186(42.7)$ & 338 (39.6) & \\
\hline College/university & $130(29.8)$ & $219(25.6)$ & \\
\hline Current $^{\mathrm{b}}$ smoking, $\mathrm{n}(\%)$ & & & $<0.001$ \\
\hline Never & $203(46.6)$ & $240(28.1)$ & \\
\hline Former & $214(49.1)$ & $488(57.1)$ & \\
\hline Current & $19(4.4)$ & $126(14.8)$ & \\
\hline Family history of PD, n (\%) & & & $<0.001$ \\
\hline None & $375(86.0)$ & 797 (93.3) & \\
\hline $\begin{array}{l}\text { At least one first-degree } \\
\text { relative diagnosed with PD }\end{array}$ & $61(14.0)$ & $57(6.7)$ & \\
\hline $\begin{array}{l}\text { Occupational exposure to } \\
\text { pesticides, } \mathrm{n}(\%)^{\mathrm{d}}\end{array}$ & & & 0.45 \\
\hline Never & $337(77.3)$ & $676(79.2)$ & \\
\hline Low & $25(5.7)$ & $55(6.4)$ & \\
\hline High & $74(17.0)$ & $123(14.4)$ & \\
\hline Area SES, median (IQR) ${ }^{c}$ & $\begin{array}{l}20.3 \\
(18.7-20.3)\end{array}$ & $\begin{array}{l}20.3 \\
(18.7-20.3)\end{array}$ & 0.39 \\
\hline
\end{tabular}

Abbreviations: $\mathrm{PD}=$ Parkinson's disease; $\mathrm{SES}=$ socioeconomic status.

${ }^{\text {a }}$ Age on which questionnaire was complete in cases and controls.

b Current, meaning before onset of PD.

c Social economic status is based on area level, percentage of high income is depicted.

${ }^{\mathrm{d}}$ Occupational pesticide exposure assigned using a job exposure matrix (JEM).

highest exposed individuals compared to those in the reference category for both the unadjusted and adjusted models (Table 3). For the fully adjusted model (model 2), $\mathrm{PM}_{2.5}$ absorbance showed significantly decreased ORs in the highest exposure category (OR 0.57, 95\% CI 0.35 , 0.96). An increased OR was observed comparing the second quartile of $\mathrm{NO}_{2}$ exposure to the first quartile (OR for model 2: $1.14,95 \% \mathrm{CI}$ : $0.76,1.70$ ) however for the higher exposure categories, the ORs attenuated to the null (OR for highest quartile: 0.87, 95\%: 0.54, 1.41). For $\mathrm{PM}_{2.5}$, the OR associated with an increase from the first quartile $\mathrm{PM}_{2.5}$ $\left(<21.2 \mu \mathrm{g} / \mathrm{m}^{3}\right)$ to the fourth $\left(>22.3 \mu \mathrm{g} / \mathrm{m}^{3}\right)$ was 0.50 (95\% CI: 0.24 , 1.01). No significant exposure-response trends were observed for any models or pollutants.

\subsection{Sensitivity analyses}

Including residential exposure to pesticides in alternative models had no appreciable effect on the main findings of the current paper. For example, the OR for $\mathrm{NO}_{2}$ and PD risk was not materially changed if exposure to pesticides was included in regression models as either a continuous variable (OR: $0.87,95 \% \mathrm{CI}: 0.53,1.41$ ) or as a binary variable (ever/never exposed; OR: 0.88, 95\% CI: 0.53, 1.45, Table S2).

Further sensitivity analyses, including considering exposure as a continuous variable did not show any notable difference as compared to the overall results (Table 3 ) nor did excluding each control disease one at a time (data not shown). Further, no heterogeneity was observed between the study centres. Stratification by smoking status revealed that ORs for never-smokers were similar to the ORs for the overall population, with the exceptions of $\mathrm{PM}_{2.5}$ absorbance and $\mathrm{PM}_{2.5}$ where we observed lower and more significant ORs in the never smokers population than in the smokers population (Table 4). However, in both groups the ORs remained below the null as in the overall analysis. When we stratified by smoking and gender (Supplement Table S3), an increase in the ORs were detected among never-smoking women for all pollutants, with OR estimates above 1 for the highest quartiles of $\mathrm{NO}_{2}$, 
Table 2

Distribution of Air pollution exposure for PD patients and controls.

\begin{tabular}{|c|c|c|c|c|c|c|c|}
\hline & \multicolumn{3}{|l|}{ PD patients } & \multicolumn{3}{|l|}{ Controls } & \multirow[t]{3}{*}{$P$ value } \\
\hline & \multicolumn{3}{|l|}{$(n=436)$} & \multicolumn{3}{|l|}{$(\mathrm{n}=854)$} & \\
\hline & Mean (SD) & $\mathrm{p} 10^{\mathrm{a}}$ & $\mathrm{p} 90^{\mathrm{b}}$ & Mean (SD) & $\mathrm{p} 10^{\mathrm{a}}$ & $\mathrm{p} 90^{\mathrm{b}}$ & \\
\hline $\mathrm{PM}_{10}, \mu \mathrm{g} / \mathrm{m}^{3}$ & $31.9(1.1)$ & 30.6 & 33.4 & $31.9(1.1)$ & 30.7 & 33.4 & 0.78 \\
\hline $\mathrm{PM}_{\text {coarse, }} \mu \mathrm{g} / \mathrm{m}^{3}$ & $10.3(0.5)$ & 9.8 & 11.0 & $10.4(0.5)$ & 9.8 & 11.1 & 0.46 \\
\hline $\mathrm{PM}_{2.5}, \mu \mathrm{g} / \mathrm{m}^{3}$ & $21.6(0.9)$ & 20.3 & 22.6 & $21.6(0.9)$ & 20.3 & 22.6 & 0.68 \\
\hline $\mathrm{PM}_{2.5}$ absorbance, $10^{-5} \mathrm{~m}^{-1}$ & $1.42(0.21)$ & 1.12 & 1.67 & $1.43(0.21)$ & 1.14 & 1.65 & 0.51 \\
\hline $\mathrm{NO}_{2}, \mu \mathrm{g} / \mathrm{m}^{3}$ & $26.4(5.4)$ & 18.8 & 33.6 & $26.6(5.3)$ & 19.5 & 32.9 & 0.32 \\
\hline $\mathrm{NO}_{\mathrm{x}}, \mu \mathrm{g} / \mathrm{m}^{3}$ & $43.2(8.6)$ & 33.2 & 53.4 & $43.4(8.7)$ & 33.5 & 53.1 & 0.58 \\
\hline
\end{tabular}

Abbreviation: $\mathrm{PD}=$ Parkinson's disease.

a 10 th percentile.

b 90 th percentile.

Table 3

Conditional logistic regression analysis for the association between PD and exposure to air pollution.

\begin{tabular}{|c|c|c|c|c|c|c|}
\hline & Unadjusted model & Trend & Model $1^{\mathrm{a}}$ & Trend & Model $2^{\mathrm{b}}$ & Trend \\
\hline & OR $(95 \% \mathrm{CI})$ & $P$ value & OR $(95 \% \mathrm{CI})$ & $P$ value & OR $(95 \% \mathrm{CI})$ & $P$ value \\
\hline \multicolumn{7}{|l|}{$\mathrm{NO}_{2}\left(\mu \mathrm{g} / \mathrm{m}^{3}\right)$} \\
\hline $\mathrm{Q} 1(\leq 22.8)$ & Reference & 0.16 & Reference & 0.40 & Reference & 0.28 \\
\hline $\mathrm{Q} 2(>22.8-\leq 26.9)$ & $1,12(0.77-1.63)$ & & $1.17(0.78-1.74)$ & & $1.14(0.76-1.70)$ & \\
\hline Q3 $(>26.9-\leq 30.4)$ & $0.90(0.60-1.36)$ & & $0.94(0.61-1.44)$ & & $0.89(0.58-1.38)$ & \\
\hline $\mathrm{Q} 4(>30.4)$ & $0.82(0.52-1.28)$ & & $0.92(0.57-1.48)$ & & $0.87(0.54-1.41)$ & \\
\hline Linear relationship (Per $10 \mu \mathrm{g} / \mathrm{m}^{3}$ ) & $0.86(0.63-1.16)$ & & $0.9(0.65-1.24)$ & & $0.86(0.62-1.19)$ & \\
\hline \multicolumn{7}{|l|}{$\mathrm{NO}_{\mathrm{x}}\left(\mu \mathrm{g} / \mathrm{m}^{3}\right)$} \\
\hline Q1 $(\leq 38.0)$ & Reference & 0.76 & Reference & 0.98 & Reference & 0.89 \\
\hline $\mathrm{Q} 2(>38.0-\leq 42.2)$ & $0.87(0.60-1.27)$ & & $0.93(0.62-1.38)$ & & $0.93(0.62-1.38)$ & \\
\hline Q3 $(>42.2-\leq 47.8)$ & $0.78(0.52-1.16)$ & & $0.80(0.53-1.22)$ & & $0.79(0.51-1.20)$ & \\
\hline $\mathrm{Q} 4(>47.8)$ & $0.93(0.62-1.40)$ & & $1.01(0.66-1.56)$ & & $0.98(0.64-1.52)$ & \\
\hline Linear relationship (Per $20 \mu \mathrm{g} / \mathrm{m}^{3}$ ) & $0.91(0.66-1.26)$ & & $0.93(0.67-1.3)$ & & $0.91(0.65-1.28)$ & \\
\hline \multicolumn{7}{|l|}{$\mathrm{PM}_{2.5}$ absorbance $\left(10^{-5} \mathrm{~m}^{-1}\right)$} \\
\hline $\mathrm{Q} 1(\leq 1.3)$ & Reference & 0.21 & Reference & 0.39 & Reference & 0.28 \\
\hline $\mathrm{Q} 2(>1.3-\leq 1.4)$ & $0.51(0.32-0.80)$ & & $0.50(0.31-0.80)$ & & $0.50(0.31-0.81)$ & \\
\hline $\mathrm{Q} 3(>1.4-\leq 1.5)$ & $0.56(0.35-0.89)$ & & $0.59(0.36-0.96)$ & & $0.58(0.35-0.95)$ & \\
\hline $\mathrm{Q} 4(>1.5)$ & $0.57(0.36-0.92)$ & & $0.60(0.36-0.99)$ & & $0.57(0.35-0.96)$ & \\
\hline Linear relationship (per $1 \times 10^{-5} \mathrm{~m}^{-1}$ ) & $0.78(0.37-1.65)$ & & $0.82(0.37-1.83)$ & & $0.77(0.34-1.73)$ & \\
\hline \multicolumn{7}{|l|}{$\mathrm{PM}_{\text {coarse }}\left(\mu \mathrm{g} / \mathrm{m}^{3}\right)$} \\
\hline Q1 $(\leq 10.0)$ & Reference & 0.56 & Reference & 0.69 & Reference & 0.54 \\
\hline $\mathrm{Q} 2(>10.0-\leq 10.3)$ & $0.89(0.62-1.26)$ & & $0.94(0.65-1.37)$ & & $0.94(0.65-1.36)$ & \\
\hline Q3 $(>10.3-\leq 10.6)$ & $1.02(0.70-1.50)$ & & $1.07(0.71-1.60)$ & & $1.04(0.69-1.56)$ & \\
\hline Q4 $(>10.6)$ & $0.84(0.55-1.28)$ & & $0.87(0.56-1.37)$ & & $0.83(0.53-1.31)$ & \\
\hline Linear relationship (per $5 \mu \mathrm{g} / \mathrm{m}^{3}$ ) & $0.59(0.14-2.45)$ & & $0.58(0.13-2.57)$ & & $0.47(0.1-2.15)$ & \\
\hline \multicolumn{7}{|l|}{$\mathrm{PM}_{2.5}(\mu \mathrm{g} / \mathrm{m} 3)$} \\
\hline $\mathrm{Q} 1(\leq 21.2)$ & Reference & 0.06 & Reference & 0.10 & Reference & 0.12 \\
\hline $\mathrm{Q} 2(>21.2-\leq 21.7)$ & $0.54(0.33-0.90)$ & & $0.52(0.31-0.87)$ & & $0.53(0.31-0.90)$ & \\
\hline Q3 $(>21.7-\leq 22.3)$ & $0.57(0.31-1.02)$ & & $0.60(0.32-1.12)$ & & $0.61(0.32-1.15)$ & \\
\hline $\mathrm{Q} 4(>22.3)$ & $0.47(0.24-0.91)$ & & $0.48(0.24-0.98)$ & & $0.50(0.24-1.01)$ & \\
\hline Linear relationship (per $5 \mu \mathrm{g} / \mathrm{m}^{3}$ ) & $0.76(0.21-2.78)$ & & $0.76(0.19-3.01)$ & & $0.8(0.2-3.17)$ & \\
\hline \multicolumn{7}{|l|}{$\mathrm{PM}_{10}\left(\mu \mathrm{g} / \mathrm{m}^{3}\right)$} \\
\hline $\mathrm{Q} 1(\leq 31.1)$ & Reference & 0.55 & Reference & 0.58 & Reference & 0.40 \\
\hline $\mathrm{Q} 2(>31.1-\leq 31.9)$ & $0.80(0.56-1.15)$ & & $0.76(0.52-1.11)$ & & $0.73(0.50-1.07)$ & \\
\hline Q3 $(>31.9-\leq 32.6)$ & $0.90(0.60-1.34)$ & & $0.91(0.60-1.38)$ & & $0.87(0.57-1.34)$ & \\
\hline $\mathrm{Q} 4(>32.6)$ & $0.84(0.55-1.30)$ & & $0.83(0.53-1.32)$ & & $0.77(0.48-1.23)$ & \\
\hline Linear relationship (per $\mu \mathrm{g} / \mathrm{m}^{3}$ ) & $0.82(0.2-3.34)$ & & $0.83(0.18-3.71)$ & & $0.68(0.15-3.1)$ & \\
\hline
\end{tabular}

a Model 1 was adjusted for educational level, smoking status and family history of PD.

b Model 2 was adjusted as in model 1, but also for area-level socioeconomic status.

(OR for Q4: $2.39,95 \%$ CI 0.72, 7.94) $\mathrm{NO}_{\mathrm{x}}$ (OR: 1.50, 95\% CI 0.56, 4.03) and $\mathrm{PM}_{\text {coarse }}(\mathrm{OR}: 1.27,95 \% \mathrm{CI}: 0.54,2.96)$.

In an analysis restricted to the population that did not move for 14 years after 1992 (251 cases and 497 controls - unconditional regression) we observed ORs slightly higher than those in the main analysis, however no significant associations were found (OR 0.78 (95\%CI 0.42, 1.46) for $\mathrm{PM}_{2.5}$ absorbance and OR 0.71 (95\% CI 0.36, 1.38 for $\mathrm{PM}_{2.5}$ ) (Supplement Table S4). Alternatively, the ORs increased when restricted to the population that did not move for 14 years before 1992 (226 cases and 406 controls) the ORs increased, showing a positive association in almost all pollutants (OR 1.50 [95\% CI 0.78, 2.91] for $\mathrm{PM}_{2.5}$ absorbance, 1.37 [0.7, 2.67] for $\mathrm{NO}_{2}, 1.56$ [0.87, 2.80] for $\mathrm{NO}_{\mathrm{x}}, 1.45[0.86,2.46]$ for $\mathrm{PM}_{\text {coarse }}$, and $1.33[0.82,2.15]$ for $\mathrm{PM}_{10}$ ) (Table 5). To further investigate these positive associations, we repeated the main analysis using the estimate of each pollutant measured in 1992. No differences were found with the main results (Table S6). 
Table 4

Stratified analysis by Smoking status for the association between PD and exposure to air pollution.

\begin{tabular}{|c|c|c|c|c|c|c|}
\hline & Crude model $^{\mathrm{a}}$ & Trend & Model $1^{\mathrm{b}}$ & Trend & Model $2^{\mathrm{c}}$ & Trend \\
\hline & OR $(95 \% \mathrm{CI})$ & $P$ value & OR $(95 \% \mathrm{CI})$ & $P$ value & OR $(95 \% \mathrm{CI})$ & $P$ value \\
\hline \multicolumn{7}{|c|}{ Never smokers $(\mathrm{N}=443 ; 203$ cases and 240 controls $)$} \\
\hline \multicolumn{7}{|c|}{$\mathrm{PM}_{2.5}$ absorbance $\left(10^{-5} \mathrm{~m}^{-1}\right)$} \\
\hline $\mathrm{Q} 1(\leq 1.3)$ & Reference & 0.14 & Reference & 0.14 & Reference & 0.11 \\
\hline $\mathrm{Q} 2(>1.3-\leq 1.4)$ & $0.47(0.24-0.90)$ & & $0.42(0.22-0.82)$ & & $0.43(0.22-0.83)$ & \\
\hline $\mathrm{Q} 3(>1.4-\leq 1.5)$ & $0.57(0.28-1.15)$ & & $0.55(0.27-1.13)$ & & $0.55(0.27-1.11)$ & \\
\hline $\mathrm{Q} 4(>1.5)$ & $0.47(0.23-0.95)$ & & $0.45(0.22-0.91)$ & & $0.44(0.21-0.89)$ & \\
\hline \multicolumn{7}{|l|}{$\mathrm{PM}_{2.5}(\mu \mathrm{g} / \mathrm{m} 3)$} \\
\hline $\mathrm{Q} 1(\leq 21.2)$ & Reference & 0.14 & Reference & 0.15 & Reference & 0.17 \\
\hline Q2 $(>21.2-\leq 21.7)$ & $0.41(0.20-0.85)$ & & $0.37(0.18-0.78)$ & & $0.38(0.18-0.80)$ & \\
\hline Q3 $(>21.7-\leq 22.3)$ & $0.50(0.23-1.08)$ & & $0.46(0.21-1.00)$ & & $0.47(0.21-1.02)$ & \\
\hline $\mathrm{Q} 4(>22.3)$ & $0.40(0.18-0.88)$ & & $0.38(0.17-0.85)$ & & $0.39(0.18-0.87)$ & \\
\hline \multicolumn{7}{|c|}{ Smokers $(\mathrm{N}=847 ; 233$ cases and 614 controls $)$} \\
\hline \multicolumn{7}{|c|}{$\mathrm{PM}_{2.5}$ absorbance $\left(10^{-5} \mathrm{~m}^{-1}\right)$} \\
\hline $\mathrm{Q} 1(\leq 1.3)$ & Reference & 0.80 & Reference & 0.90 & Reference & 0.78 \\
\hline $\mathrm{Q} 2(>1.3-\leq 1.4)$ & $0.62(0.35-1.11)$ & & $0.60(0.34-1.07)$ & & $0.60(0.34-1.08)$ & \\
\hline $\mathrm{Q} 3(>1.4-\leq 1.5)$ & $0.64(0.36-1.14)$ & & $0.60(0.33-1.08)$ & & $0.59(0.32-1.07)$ & \\
\hline $\mathrm{Q} 4(>1.5)$ & $0.83(0.46-1.47)$ & & $0.77(0.43-1.38)$ & & $0.75(0.41-1.35)$ & \\
\hline \multicolumn{7}{|l|}{$\mathrm{PM}_{2.5}(\mu \mathrm{g} / \mathrm{m} 3)$} \\
\hline $\mathrm{Q} 1(\leq 21.2)$ & Reference & 0.92 & Reference & 0.70 & Reference & 0.74 \\
\hline $\mathrm{Q} 2(>21.2-\leq 21.7)$ & $0.74(0.40-1.35)$ & & $0.77(0.42-1.42)$ & & $0.79(0.43-1.44)$ & \\
\hline Q3 $(>21.7-\leq 22.3)$ & $0.84(0.46-1.53)$ & & $0.88(0.48-1.63)$ & & $0.89(0.48-1.64)$ & \\
\hline Q4 (> 22.3) & $0.79(0.43-1.48)$ & & $0.79(0.42-1.48)$ & & $0.80(0.43-1.51)$ & \\
\hline
\end{tabular}

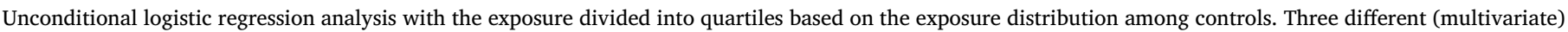
models are shown. Each model is additionally adjusted by age, sex and center.

a The crude model shows ORs adjusted only by age, sex and center.

b Model 1 was additionally adjusted for educational level, smoking status and family history of PD.

c Model 2 was adjusted as in model 1, but also for area-level socioeconomic status.

Finally, in order to assess whether these positive ORs could be attributed to the rural or urban setting of non-movers, we stratified the stability analysis by urbanized area (high vs low) that the participant lived at in 1992. A highly urbanized area was defined as one with $>1500$ addresses $/ \mathrm{km}^{2}$ in the neighbourhood of the residence, a standard definition in the Netherlands (Brouwer et al., 2017). Individuals who did not move for 14 years prior to 1992 were mostly participants who lived in a rural setting (148 out of 224 cases and 265 out of 397 controls). The ORs presented in the group of low urbanization remained above unity and for some pollutants were higher than in the non-stratified analysis (ORs 2.24 (95\% CI 0.80, 6.27) for $\mathrm{PM}_{2.5}$ absorbance and OR 2.10 (95\% CI 0.61, 7.20) for $\mathrm{PM}_{2.5}$. (Supplement Table S7).

\section{Discussion}

In a Dutch case-control study, we observed no statistically significant positive associations between up to 16 years to exposure to different air pollution constituents and PD. Instead, most ORs were below unity. In sub-group analyses, we found ORs above unity for those with long-term residential stability and among non-smoking women, however with wider confidence intervals. While these findings may reflect the absence of a true association between exposure to ambient air pollution and $\mathrm{PD}$, it is possible that, for at least $\mathrm{PM}_{2.5}$ and $\mathrm{PM}_{10}$, there was insufficient contrast in air pollution exposure to identify risks. However, for $\mathrm{NO}_{2}, \mathrm{NO}_{\mathrm{x}}$ and $\mathrm{PM}_{2.5}$ absorbance the contrast was comparable to other studies. We note that the matching by hospital implies that regional contrast in air pollution could not be exploited. $\mathrm{NO}_{2}$ is more affected by local sources while $\mathrm{PM}_{2.5}$ is more a regionally varying pollutant with limited local variation. Lee et al. identified a positive role of $\mathrm{NO}_{\mathrm{x}}$ in their study of Taiwanese residents with $\mathrm{NO}_{\mathrm{x}}$ exposures ranging from approximately 10 to $150 \mu \mathrm{g} / \mathrm{m}^{3}$ (median $50 \mu \mathrm{g} / \mathrm{m}^{3}$ ). By comparison, we observed a similar exposure range of 22 to $113 \mu \mathrm{g} / \mathrm{m}^{3}$ (median $40 \mu \mathrm{g} / \mathrm{m}^{3}$ ) for $\mathrm{NO}_{\mathrm{x}}$. The range of $\mathrm{NO}_{2}$ exposure reported in the current study $\left(14-48 \mu \mathrm{g} / \mathrm{m}^{3}\right.$, median $\left.27 \mu \mathrm{g} / \mathrm{m}^{3}\right)$ is comparable to those reported by Ritz et al. (Ritz et al., 2016) in their reporting of a positive association between ambient air pollution and PD (10 to $43 \mu \mathrm{g} / \mathrm{m}^{3}$, median $12 \mu \mathrm{g} / \mathrm{m}^{3}$ ).

A further consideration is that of disease development, which might not be sufficiently covered by the exposure period considered in the current study. Air pollution was modelled from the year 1992 to the year prior to PD diagnosis (average 16 years). The development of PD is a chronic condition, with a latency of 12 to 14 years between development of "non-motor" symptoms (some of which - such as constipation and mood changes are not specific to PD) and the PD symptoms required for diagnosis (rigidity, tremor etc.) (Postuma et al., 2012). Therefore, we may have an insufficient level of follow-up to identify associations. This may be reflected in our analysis of those with longterm residential stability before and after 1992 where an increased risk of PD was observed. For these individuals, the average exposures modelled would represent their exposures experienced over a longer course than other participants (assuming that spatial concentration patterns remained stable), therefore allowing a more long-term representation of the relationship between ambient air pollution and PD development. The complication of this analysis is that by restricting to a stable population we were selecting for more rural settings as 413 of the 621 people with long term residential stability were living in rural areas. However, stratifying by rural/urban status within the stable population showed similar results between these strata (Table S7), albeit with increasing uncertainty as sample sizes reduced substantially. Residential exposures to air pollution in rural areas are generally somewhat lower than urban areas (e.g. the average concentrations of $\mathrm{NO}_{2}$ for urban and rural areas were 31.2 and $24.2 \mu \mathrm{g} / \mathrm{m}^{3}$ respectively), therefore an alternative explanation may be that other rural exposures are related to PD risk. We examined the possibility of residential exposure to pesticides within the main population, which was found to not influence findings (Table S2).

Additional considerations in disease aetiology are occupational exposures and family histories of disease. We observed no significant difference in occupational exposure to pesticides between cases and controls, however we did observe a higher likelihood of familial history 
Table 5

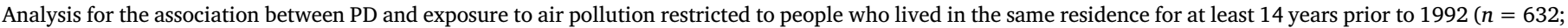
226 cases and 406 controls).

\begin{tabular}{|c|c|c|c|c|c|c|}
\hline & Unadjusted model $^{\mathrm{a}}$ & Trend & Model $1^{\mathrm{b}}$ & Trend & Model $2^{c}$ & Trend \\
\hline & OR $(95 \% \mathrm{CI})$ & $P$ value & OR $(95 \% \mathrm{CI})$ & $P$ value & OR $(95 \% \mathrm{CI})$ & $P$ value \\
\hline \multicolumn{7}{|l|}{$\mathrm{NO}_{2}\left(\mu \mathrm{g} / \mathrm{m}^{3}\right)$} \\
\hline $\mathrm{Q} 1(\leq 22.8)$ & Reference & 0.81 & Reference & 0.61 & Reference & 0.81 \\
\hline $\mathrm{Q} 2(>22.8-\leq 26.9)$ & $1.35(0.78-2.33)$ & & $1.50(0.85-2.67)$ & & $1.45(0.81-2.59)$ & \\
\hline Q3 $(>26.9-\leq 30.4)$ & $1.00(0.55-1.79)$ & & $1.00(0.55-1.85)$ & & $0.94(0.51-1.75)$ & \\
\hline Q4 $(>30.4)$ & $1.29(0.69-2.40)$ & & $1.49(0.78-2.86)$ & & $1.37(0.71-2.67)$ & \\
\hline \multicolumn{7}{|l|}{$\mathrm{NO}_{\mathrm{x}}\left(\mu \mathrm{g} / \mathrm{m}^{3}\right)$} \\
\hline $\mathrm{Q} 1(\leq 38.0)$ & Reference & 0.20 & Reference & 0.14 & Reference & 0.19 \\
\hline $\mathrm{Q} 2(>38.0-\leq 42.2)$ & $1.04(0.60-1.79)$ & & $1.15(0.65-2.03)$ & & $1.15(0.65-2.04)$ & \\
\hline Q3 $(>42.2-\leq 47.8)$ & $0.90(0.52-1.55)$ & & $0.95(0.53-1.68)$ & & $0.94(0.53-1.67)$ & \\
\hline Q4 (> 47.8) & $1.46(0.84-2.56)$ & & $1.61(0.90-2.89)$ & & $1.56(0.87-2.80)$ & \\
\hline \multicolumn{7}{|c|}{$\mathrm{PM}_{2.5}$ absorbance $\left(10^{-5} \mathrm{~m}^{-1}\right)$} \\
\hline $\mathrm{Q} 1(\leq 1.3)$ & Reference & 0.28 & Reference & 0.22 & Reference & 0.29 \\
\hline $\mathrm{Q} 2(>1.3-\leq 1.4)$ & $1.18(0.64-2.17)$ & & $1.26(0.66-2.39)$ & & $1.31(0.68-2.50)$ & \\
\hline $\mathrm{Q} 3(>1.4-\leq 1.5)$ & $1.12(0.60-2.09)$ & & $1.27(0.66-2.43)$ & & $1.27(0.66-2.43)$ & \\
\hline $\mathrm{Q} 4(>1.5)$ & $1.43(0.76-2.69)$ & & $1.53(0.79-2.95)$ & & $1.50(0.78-2.91)$ & \\
\hline \multicolumn{7}{|l|}{$\mathrm{PM}_{\text {coarse }}\left(\mu \mathrm{g} / \mathrm{m}^{3}\right)$} \\
\hline $\mathrm{Q} 1(\leq 10.0)$ & Reference & 0.26 & Reference & 0.09 & Reference & 0.11 \\
\hline $\mathrm{Q} 2(>10.0-\leq 10.3)$ & $1.16(0.73-1.85)$ & & $1.17(0.72-1.90)$ & & $1.19(0.73-1.93)$ & \\
\hline Q3 $(>10.3-\leq 10.6)$ & $1.28(0.80-2.04)$ & & $1.48(0.91-2.41)$ & & $1.46(0.89-2.38)$ & \\
\hline Q4 (> 10.6) & $1.30(0.78-2.16)$ & & $1.48(0.88-2.51)$ & & $1.45(0.86-2.46)$ & \\
\hline \multicolumn{7}{|l|}{$\mathrm{PM}_{2.5}(\mu \mathrm{g} / \mathrm{m} 3)$} \\
\hline $\mathrm{Q} 1(\leq 21.2)$ & Reference & 0.62 & Reference & 0.30 & Reference & 0.27 \\
\hline $\mathrm{Q} 2(>21.2-\leq 21.7)$ & $0.62(0.33-1.16)$ & & $0.58(0.30-1.11)$ & & $0.59(0.31-1.12)$ & \\
\hline Q3 $(>21.7-\leq 22.3)$ & $0.78(0.40-1.49)$ & & $0.87(0.45-1.71)$ & & $0.90(0.46-1.76)$ & \\
\hline Q4 (> 22.3) & $0.86(0.44-1.67)$ & & $0.93(0.47-1.86)$ & & $0.95(0.48-1.90)$ & \\
\hline \multicolumn{7}{|l|}{$\mathrm{PM}_{10}\left(\mu \mathrm{g} / \mathrm{m}^{3}\right)$} \\
\hline $\mathrm{Q} 1(\leq 31.1)$ & Reference & 0.19 & Reference & 0.08 & Reference & 0.11 \\
\hline $\mathrm{Q} 2(>31.1-\leq 31.9)$ & $0.86(0.54-1.39)$ & & $0.88(0.54-1.43)$ & & $0.87(0.53-1.42)$ & \\
\hline $\mathrm{Q} 3(>31.9-\leq 32.6)$ & $1.17(0.74-1.85)$ & & $1.35(0.83-2.18)$ & & $1.34(0.83-2.16)$ & \\
\hline $\mathrm{Q} 4(>32.6)$ & $1.27(0.80-2.01)$ & & $1.38(0.85-2.22)$ & & $1.33(0.82-2.15)$ & \\
\hline
\end{tabular}

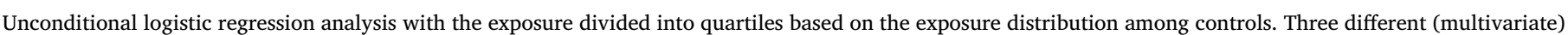
models are shown. Each model is additionally adjusted by age, sex and center.

a The crude model shows ORs adjusted only by age, sex and center.

b Model 1 was adjusted for educational level, smoking status and family history of PD.

c Model 2 was adjusted as in model 1, but also for area-level socioeconomic status.

of Parkinson's disease among cases. While this may speak to the familial component in PD development, we cannot rule out familial commonalities in occupation or exposure. Additionally, we observed that cases were more likely to be highly educated (29.8\%) than controls $(25.6 \%)$, which may reflect previous findings of higher PD risk among "white collar" occupations (e.g. office work) and highly educated individuals (Yang et al., 2016; Beard et al., 2017; Frigerio et al., 2005). In a posthoc data review, we broadly categorized our cases and controls into "white collar" and "blue collar" professions, and observed that cases were slightly more likely to be white collar workers $(64 \%)$ than controls $(60 \%)$ although this difference was non-significant $(p=0.14)$.

An additional consideration is that smoking related morbidity and mortality within the potential control population may have contributed somewhat to selection bias. Controls were more likely to be current or former smokers, which is consistent with previous literature which reports lower likelihood of PD among smokers. We attempted to evaluate any additional role of smoking within our study population within our sensitivity analysis where we examined smokers and non-smokers separately, observing similar findings to those in the main analysis (Table 4).

The current study used a well-defined population with strong information on lifestyle factors and utilised robust, extensively used exposure models. Our sub-group analysis finding of elevated risks for nonsmoking women (similar to the increased risks among women and nonsmokers reported by Liu et al. (Liu et al., 2016) and among those with extended residential stability - deserve further exploration.

\section{Conclusions}

This study reports no significant positive association between exposure to ambient air pollution for a period of 16 years and the development of Parkinson's disease. In sub-group analysis we found evidence to suggest that non-smoking women and those with long-term residential stability may be at elevated risk with increased exposure to ambient air pollution, however limited sample size in this subgroup restricts the reliability of these findings. Additional work, considering longer exposure times may assist in further understanding what (if any) role ambient air pollution plays in the risk of developing PD.

\section{Appendix A. Supplementary data}

Supplementary data to this article can be found online at https:// doi.org/10.1016/j.envint.2019.04.069.

\section{References}

Beard, J.D., Steege, A.L., Ju, J., Lu, J., Luckhaupt, S.E., Schubauer-Berigan, M.K., 2017. Mortality from amyotrophic lateral sclerosis and Parkinson's disease among different occupation groups - United States, 1985-2011. MMWR Morb. Mortal. Wkly Rep. 66 (27), 718-722. https://doi.org/10.15585/mmwr.mm6627a2.

Beelen, R., Hoek, G., Vienneau, D., et al., 2013. Development of NO2 and NOx land use regression models for estimating air pollution exposure in 36 study areas in Europe the ESCAPE project. Atmos. Environ. 72, 10-23. https://doi.org/10.1016/j. atmosenv.2013.02.037.

Beelen, R., Raaschou-Nielsen, O., Stafoggia, M., et al., 2014. Effects of long-term exposure 
to air pollution on natural-cause mortality: an analysis of 22 European cohorts within the multicentre ESCAPE project. Lancet 383 (9919), 785-795. https://doi.org/10. 1016/S0140-6736(13)62158-3.

Block, M.L., Calderon-Garciduenas, L., 2009. Air pollution: mechanisms of neuroinflammation and CNS disease. Trends Neurosci. 32 (9), 506-516. https://doi.org/10. 1016/j.tins.2009.05.009.

Block, M.L., Elder, A., Auten, R.L., et al., 2012. The outdoor air pollution and brain health workshop. Neurotoxicology 33 (5), 972-984. https://doi.org/10.1016/j.neuro.2012. 08.014 .

Brouwer, M., Huss, A., van der Mark, M., et al., 2017. Environmental exposure to pesticides and the risk of Parkinson's disease in the Netherlands. Environ. Int. 107, 100-110 (doi: S0160-4120(17)30075-2 [pii).

Cerza, F., Renzi, M., Agabiti, N., et al., 2018. Residential exposure to air pollution and incidence of Parkinson's disease in a large metropolitan cohort. Environ. Epidemiol. 2 (3). https://journals.lww.com/environepidem/Fulltext/2018/09000/Residential exposure to air pollution and.5.aspx.

Chen, C.Y., Hung, H.J., Chang, K.H., et al., 2017. Long-term exposure to air pollution and the incidence of Parkinson's disease: a nested case-control study. PLoS One 12 (8), e0182834. https://doi.org/10.1371/journal.pone.0182834.

Dorsey, E.R., Constantinescu, R., Thompson, J.P., et al., 2007. Projected number of people with Parkinson disease in the most populous nations, 2005 through 2030. Neurology 68 (5), 384-386 (doi: 01.wnl.0000247740.47667.03 [pii).

Eeftens, M., Beelen, R., de Hoogh, K., et al., 2012. Development of land use regression models for PM(2.5), PM(2.5) absorbance, PM(10) and PM(coarse) in 20 European study areas; results of the ESCAPE project. Environ. Sci. Technol. 46 (20), 11195-11205. https://doi.org/10.1021/es301948k.

Finkelstein, M.M., Jerrett, M., 2007. A study of the relationships between Parkinson's disease and markers of traffic-derived and environmental manganese air pollution in two Canadian cities. Environ. Res. 104 (3), 420-432 (doi: S0013-9351(07)00054-0 pii]).

Frigerio, R., Elbaz, A., Sanft, K.R., et al., 2005. Education and occupations preceding Parkinson disease: a population-based case-control study. Neurology 65 (10), 1575-1583 (doi: 65/10/1575 [pii).

Hay, S.I., Abajobir, A.A., Abate, K.H., et al., 2017. Global, regional, and national disability-adjusted life-years (DALYs) for 333 diseases and injuries and healthy life expectancy (HALE) for 195 countries and territories, 1990-2016: a systematic analysis for the global burden of disease study 2016. Lancet 390 (10100), 1260-1344. https:// doi.org/10.1016/S0140-6736(17)32130-X.

Higgins, J.P., Thompson, S.G., 2002. Quantifying heterogeneity in a meta-analysis. Stat. Med. 21 (11), 1539-1558. https://doi.org/10.1002/sim.1186.

Kalia, L.V., Lang, A.E., 2015. Parkinson's disease. Lancet 386 (9996), 896-912. https://
doi.org/10.1016/S0140-6736(14)61393-3.

Lee, P.C., Liu, L.L., Sun, Y., et al., 2016. Traffic-related air pollution increased the risk of Parkinson's disease in Taiwan: a nationwide study. Environ. Int. 96, 75-81(doi: S0160-4120(16)30307-5 pii).

Liu, R., Young, M.T., Chen, J.C., Kaufman, J.D., Chen, H., 2016. Ambient air pollution exposures and risk of Parkinson disease. Environ. Health Perspect. 124 (11), 1759-1765. https://doi.org/10.1289/EHP135.

Palacios, N., Fitzgerald, K.C., Hart, J.E., et al., 2014. Particulate matter and risk of Parkinson disease in a large prospective study of women. Environ. Health 13https:// doi.org/10.1186/1476-069X-13-80. 80-069X-13-80.

Palacios, N., Fitzgerald, K.C., Hart, J.E., et al., 2017. Air pollution and risk of Parkinson's disease in a large prospective study of men. Environ. Health Perspect. 125 (8), 087011. https://doi.org/10.1289/EHP259.

Postuma, R.B., Aarsland, D., Barone, P., et al., 2012. Identifying prodromal Parkinson's disease: pre-motor disorders in Parkinson's disease. Mov. Disord. 27 (5), 617-626. https://doi.org/10.1002/mds.24996.

Ritz, B., Lee, P.C., Hansen, J., et al., 2016. Traffic-related air pollution and Parkinson's disease in Denmark: a case-control study. Environ. Health Perspect. 124 (3), 351-356. https://doi.org/10.1289/ehp.1409313.

Rossi, A., Berger, K., Chen, H., Leslie, D., Mailman, R.B., Huang, X., 2018. Projection of the prevalence of Parkinson's disease in the coming decades: revisited. Mov. Disord. 33 (1), 156-159. https://doi.org/10.1002/mds.27063.

van der Mark, M., Brouwer, M., Kromhout, H., Nijssen, P., Huss, A., Vermeulen, R., 2012. Is pesticide use related to Parkinson disease? Some clues to heterogeneity in study results. Environ. Health Perspect. 120 (3), 340-347. https://doi.org/10.1289/ehp. 1103881.

van, dM, Nijssen, P.C.G., Vlaanderen, J., et al., 2014. A case-control study of the protective effect of alcohol, coffee, and cigarette consumption on Parkinson disease risk: time-since-cessation modifies the effect of tobacco smoking. PLoS One 9 (4), e95297. http://www.ncbi.nlm.nih.gov/pmc/articles/PMC4005732/ https://doi.org/10. 1371/journal.pone.0095297.

Vos, T., Abajobir, A.A., Abate, K.H., et al., 2017. Global, regional, and national incidence, prevalence, and years lived with disability for 328 diseases and injuries for 195 countries, 1990-2016: a systematic analysis for the global burden of disease study 2016. Lancet 390 (10100), 1211-1259. https://doi.org/10.1016/S0140-6736(17) 32154-2.

Yang, F., Johansson, A.L., Pedersen, N.L., Fang, F., Gatz, M., Wirdefeldt, K., 2016. Socioeconomic status in relation to Parkinson's disease risk and mortality: a population-based prospective study. Medicine (Baltimore) 95 (30), e4337. https://doi. org/10.1097/MD.0000000000004337. 